\title{
How School Leaders Might Promote Higher Levels of Collective Teacher Efficacy at the Level of School and Team
}

\author{
Gail E. Prelli ${ }^{1}$ \\ ${ }^{1}$ University of Bridgeport, USA \\ Correspondence: Gail E. Prelli, University of Bridgeport, USA. E-mail: gprelli@bridgeport.edu
}

Received: December 21, 2015 Accepted: February 12, 2016 Online Published: February 16, 2016

doi: 10.5539/elt.v9n3p174

URL: http://dx.doi.org/10.5539/elt.v9n3p174

\begin{abstract}
Leaders search for effective leadership practices to ensure success. A quantitative study was conducted to determine what behaviors a leader could use to improve collective teacher efficacy at the level of the entire faculty and at the level of grade level teams. This article focuses on using the inverse relationship between transformational leadership and collective teacher efficacy to strengthen efficacy of teachers of English Language Learners. The Collective Efficacy Scale (Goddard, 2001) was modified to measure the perceptions of teachers at both levels; entire faculty's collective efficacy and the collective efficacy of their team. Thus, this article also provides leaders with important information regarding teaming within schools. The significant difference found between collective teacher efficacy at the level of school and team, provides important information for leaders to consider as they support professional learning teams. Success for all would be promoted as leaders increase efficacy within teams by employing the concepts of developing leadership teams and purposeful learning communities (Hill \& Lundquist, 2008).
\end{abstract}

Keywords: transformational leadership, collective teacher efficacy, English language learners, teaming

\section{Introduction}

This article reviews the results of a study that looked at collective teacher efficacy at the level of team as well as school. Findings from a study of 93 grade level teams and 15 schools showed a significant difference between collective teacher efficacy at the level of team and school. Additionally, the correlations between perceived transformational leadership actions and the perceived collective teacher efficacy at the school level and level of team was negative, evincing noteworthy significance. Using Marks, Printy, and Bowers view of transformational leadership as an intellectual and activating influence, this article provides direction for leaders to employ to establish school communities empowered to meet the challenges presented in schools today. External threats to efficacy, such as an increase in the percent of English Language Learners, are critical for a leader to note.

School leaders continue to search for the most powerful and effective practices to implement as a means to improve schools and promote higher levels of student achievement. Although the topic has been researched for years; questions still remain on the minds of leaders about the most effective leadership practices to employ to meet the challenges in schools today. A recent meta-analysis by Leithwood and Sun recognizes transformational leadership as the most widely used and tested model of leadership with proven effects on schools, teachers and students; yet cannot predict the behaviors of members within an organization. However, the analysis noted small direct effects on student achievement. The recommendations for school leaders include employing effective practice, rather than focusing on a single model (Leithwood \& Sun, 2013). A great deal of similarity exists in the literature reviewing effective leadership practice (Leithwood \& Sun, 2013; Marks \& Printy, 2003; Marzano, Waters, \& McNulty, 2004; Printy, Marks, \& Boyer, 2009) and many of the actions described overlap with Leithwood's early findings on transformational leadership emphasizing the importance of holding high expectations for students and staff, establishing a common goal, and providing intellectual stimulation, also found in the present study being described.

Recent attention has also focused on the importance for leaders to recognize the power of social networks as a means to improve schools (Coburn \& Russell, 2008). Professional Learning Communities have emphasized teacher collaboration as a means for improving student achievement (Dufour \& Eaker, 1998) and some studies go as far as to suggest teacher networks are a means for improving student achievement (Moolenaar, Sleegers, \& Daly, 2012). However, studies have shown that collective teacher efficacy has a positive effect on student 
achievement (Goddard, Hoy, \& Woolfolk, 2000).

Jane Hill and Anne Lundquist provided valuable insights for leaders to consider to better help teachers meet the needs of all students including English Language Learners. One of the suggestions included developing a leadership team and a purposeful community (Hill \& Lundquist, 2008). The article reported on significant gains made by students in a Southwestern United States rural intermediate school where teacher leadership teams were utilized. Specifically, they referenced the power of teacher support and collaboration from the leadership teams to meet the needs of the students. Through team modeling, feedback and support, teacher collective efficacy increased (Hill \& Lundquist, 2008).

\section{Theoretical Framework}

Researchers have consistently looked for actions an educational leader utilize to improve student achievement. Leadership has been shown to have a significant effect on achievement, and the only group that more greatly impacts student success is teachers (Leithwood \& Riehl, 2003; Waters, Marzano, \& McNulty, 2004). Leaders today face many challenges associated with accountability and all leaders seek to discover the best research based improvement process for their school. Major revisions in curricular standards, teacher growth plans, and assessments establish higher expectations for teachers and students have created a culture of concern with efficacy compromised. This article uses findings from a study that employed concepts of transformational leadership (Leithwood, 1993) and social cognitive theory (Bandura, 1997) to search for direction leaders could use to promote greater collective efficacy in their schools.

Transformational leadership provides direction for leaders to utilize in the change process by employing actions that influence both the group and individuals in an organization. (Leithwood, 1992; Leithwood, Jantzi, \& Steinbach, 1999). Social cognitive theory (Bandura, 1993) shows the motivation for individuals or groups if goals are perceived to be challenging yet attainable; as well as purposeful, and rewarding. Efficacy (Bandura, 1993) also provided understanding for leaders. Bandura's research was important for leaders since feedback from a superior was shown to influence a person's self-appraisal of ability. Prior to the study used for the basis of this article, Hipp had identified behaviors of transformational leadership that elementary and middle school principals could employ as a means to promote higher teacher efficacy.

Ross and Gray showed how teacher efficacy alone promoted teacher commitment to goals and transformative leadership actions of a leader, directly affected teacher commitment to a school's mission and incited professional learning. Most importantly, research has shown a connection to efficacy and student achievement through its influence on teacher performance (Bandura, 1993; Goddard, Hoy, \& Woolfolk, 2000; Goddard \& Goddard, 2001; Hipp, 1996; Hoy \& Woolfolk, 1993; Milner, 2002; Ross \& Gray, 2004).

Thus leaders that understand motivation theory might influence performance of the teachers within their schools. The study looked to determine those actions a leader might employ to influence collective teacher efficacy at the level of whole faculty and teams within the school.

\section{Transformational Leadership}

Transformational leadership theory has been around for several years. Burns was the first to introduce the concept as a means for school leaders to enact change in an organization by focusing on communication. Through interaction, a leader could engage subordinates in the change process. Bass added to the theory in 1985, highlighting the effect that transformational leaders had on employees when they helped them recognize how their contribution improved the organization. Thus a leader could motivate workers by helping them see how their actions contributed to the greater good of the group. This in turn motivates followers to work for higher levels of performance or set more ambitious goals.

Transformational leadership theory (Burns, 1978; Leithwood, 1992) provided direction for leaders to use a way to improve school culture. By developing and maintaining collaborative relationships with followers, a leader could enhance the culture within the organization. Leithwood also showed that by involving staff in addressing issues and working on issues or problems within the organization, the leader was improving the ability faculty within schools. Suggestions for this success emphasized the transformational leader's work with staff to set common goals and development of a collaborative work environment. This could be accomplished by communicating the cultural norms, values and beliefs. It is equally important to hire new faculty who share a commitment to the group's mission. The transformative leaders also empowered teams within the school to assume responsibilities. A leader's ability to influence learning was noted in a study by Leithwood and Reihl. Effective practice included a leader promoting a common vision and goals and securing the resources necessary for teachers to do their work. 
Leaders have been viewed as change agents (Leithwood, Louis, Anderson, \& Watson, 1999). Interventions that would promote change in an organization involved a leader setting direction for the improvement, closely monitoring the improvement initiative and building the capacity of workers and again providing the support needed for success. An effective leader also needs to assess and design the organization to encourage and support these collaborative initiatives.

\section{Collective Teacher Efficacy}

Collective teacher efficacy has been shown to have a positive effect on student achievement (Goddard et al., 2004). Thus, if a leader could promote higher levels of collective efficacy within the school or within teams, collective teachers' efficacy could be a means to improve student performance. Goddard and his colleagues found four ways for collective efficacy to be enhanced. The first concept is mastery experiences; ensuring and recognizing workers for their successful work. The effective leader provides the supports and resources needed to promote success within the school. The second way collective efficacy is strengthened is through vicarious experience, or watching others perform the task. This fits with the transformational leadership action of modeling. Leaders might also use social persuasion to improve collective efficacy. Telling the stories of past successes, reminding the faculty or team of their ability all provide examples of social persuasion. The last variable reported (Godard et al., 2004) from the study was affective states. This has to do with excitement and joy for the successes or the work being accomplished. Another study that looked at how a leader might improve collective teacher efficacy showed the need for a leader to emphasize successes and proved feedback to teachers on about their success (Tschannen-Moran, Woolfolk, Hoy, \& Hoy, 2001). The same study emphasized the need for leaders to ensure members of the organization maintained a focus on the goals.

\section{Transformational Leadership and Collective Teacher Efficacy}

A study by Hoy and Woolfolk demonstrated how a principal could influence personal teaching efficacy. This was later studied more in-depth by Hipp. The focus of the study looked specifically at ways a principal effect teacher efficacy. Three actions of transformational leadership could be used by a leader to promote efficacy. They actions involved a leader modeling, motivating the faculty toward a common purpose and providing contingent rewards. Hipp later researched behaviors of middle school principals and identified ten leadership behaviors that influenced teacher efficacy. Many of the ten overlapped with the earlier studies on ways leaders could promote teacher efficacy but also included empowering faculty in decision making, recognizing the efforts of faculty and working to develop a strong culture or sense of community. This was accomplished by focus on shared goals, collaborative work and encouragement for innovation and professional growth. Hipp's research highlighted the fact that teachers look to a leader for any indication of what is valued in the school. He emphasized the concept that leaders give symbolic cues which depict beliefs about what the school can accomplish. These studies stressed the influence a leader can have on teacher (Hipp, 1997).

Ross and Gray conducted a study that showed how the transformative actions of school leader impacted teachers' commitment to goals and professional learning. The same study showed that if teacher efficacy was high, there was a direct correlation to the commitment to school goals. Thus the study showed that transformational actions could influence collective teacher efficacy. Recognizing the impact that positive collective teacher efficacy has on student achievement, a leader could use these transformational behaviors.

It is important to look at the variance between the collective teacher efficacy of the faculty and that of teams within the school. It is not enough to implement the aforementioned behaviors emphasized by Hipp and Bredeson. A leader must first know the collective teacher efficacy of the team before deciding on actions to employ.

\section{Research Design and Methodology}

The information for this article comes from a study that used a correlational design to identify perceived leadership actions that had an effect on collective teacher efficacy at the level of school and team. The schools participating in the study were carefully selected to ensure that all levels of socio/economic status were represented. The study included data collected from 93 grade level teams from 15 elementary schools. Two Likert-type scales were used to determine the correlation at two levels, school and team. To measure teachers' perceptions of principals' leadership behaviors, the Nature of Leadership Scale (Leithwood \& Jantzi, 1999) was given. The scale measures perceived actions of a leader. The Collective Efficacy Scale (Goddard, 2001) was also given to measure the extent to which a faculty, as a whole, perceives their ability to improve learning. Additional items were added to measure the perceived efficacy of teams. 


\section{Data Analysis}

Pearson product correlations were run using SPSS to analyze results from both scales. The results were coded by both school and team to measure any variances between perceived efficacy of the faculty as a whole, and the collective efficacy at the level of team. Analysis included identifying significance between perceived behaviors of leaders and perceived efficacy. A paired $t$-test was used to determine whether or not the difference between the means of the perceived efficacy of the respondents' school and their grade level team was significant.

\section{Results}

The results and analysis of data presented in this article depict data gathered from 306 elementary school teachers representing 93 teams, from 15 schools representing all District Reference Groups in Connecticut. Connecticut teachers had strong perceptions of the principals to exhibit transformational behaviors. The mean of 4.73 evinced that teachers strongly agreed with the perception that leaders exhibited transformational leadership. The Pearson $r$ measuring the correlation between transformational leadership and collective teacher efficacy was -.281 and showed significance a $(p<.05)$. This negative correlation suggests that when collective efficacy is perceived to be high, teachers perceive leaders to exhibit transformative behaviors to a lesser degree. Another way of interpreting this relationship would be to say that when the perceptions of efficacy are low, the perception of transformational leadership traits is much higher.

The transformational leadership action with the highest mean related to the teachers' perception of the leader to hold high expectations for excellence and high performance on the part of teachers and students. This had an average score of 4.73 with a standard deviation of .56. The next two actions teacher perceived to be strong were the leader builds consensus (4.8595) and develops a shared vision (4.8234). These actions directly relate to the concepts of encouraging collegiality and collaboration.

Looking at the correlations between efficacy and transformational behavior, the action of a leader modeling had the strongest coefficient with collective efficacy at the level of team and was statistically significant at $p<.01$ with a correlation of -.356. This was an opposite finding from the earlier study of Hipp and Bredeson. "Model behaviors" was defined (Leithwood, Jantzi, \& Fernandez, 1993) as actions of the leader that exemplifies for others, behaviors consistent with the values the leader espouses. A leader using this information for supporting teams would first need to know the collective efficacy of that team. The negative correlation would suggest to a leader that when the teachers' collective efficacy within a grade level team is high, the less they perceive the leader to model behavior.

There were four other categories determined to be significant between perceived leadership behavior and collective teacher efficacy at the grade level team. One included a leaders action to improve culture (-.308), work toward establishing a common vision (-.285), bring the teachers to consensus about goals (-.265) and support individual teachers (-.257).

It was important to determine whether or not teachers perceived the collective efficacy for their individual grade level to be the same as they perceived the collective efficacy for the faculty. To accomplish this comparison, additional statements were added to the Collective Efficacy Scale. These statements added were parallel to the original statements but was specific to whether the teachers were rating the perceptions of faculty or team. The first comparison was a correlation between the original statements on the scale and the revised statements for team. Results showed a correlation of $.866(p<.05)$ and proved to be strong.

A paired $t$-test was used to determine whether or not the difference between the means of the perceived efficacy of the respondents' school and their grade level team was significant. The results showed significance $t(61)=-3.383, p<.05$. This is important for leaders to know and consider as they determine actions to support the faculty as a whole versus individual teams.

\section{Discussion}

The inverse correlation found in the study was not predicted and did not align with findings from earlier studies, yet provides meaningful information for leaders. The consistent negative correlations between the transformational behaviors and collective efficacy at the level of team and faculty provide leaders with a concept to look at more closely: the importance of knowing the collective efficacy within grade level teams and within their school before deciding on the transformational action to use. The study was correlational and the negative coefficients between collective teacher efficacy and transformational leadership raise questions to be studied more fully. The tight inverse relationship between collective efficacy and leadership action cannot be ignored. When leaders recognize the efficacy of their faculty is not strong they might consider being more deliberate about modeling successful practice and working to build a positive culture for learning. It would be important to 
focus on a common mission for the school and work with staff to build consensus to the school improvement initiatives. Empowering staff and creating leadership teams (Hill \& Lundquist, 2008) for grade levels teachers displaying high efficaciousness might be most appropriate. Leaders could always employ strategies to increase collective efficacy within schools or teams and capitalize on the expertise of teams. Actions such providing opportunities for collaborative sharing or teachers to observe peers implementing best practice strategies would strengthen the beliefs of teachers to be successful with the most challenging of situations. Leaders might also remember the importance of reminding followers of prior successes using persuasion as a mediator for sustaining and nurturing efficacy (Goddard et al., 2004).

The four sources for efficacy according to Goddard and his associates are: Mastery experiences, vicarious experience, social persuasion, and affective states. Little research exists about how leaders might use affective states to promote higher states of collective efficacy (Goddard, 2001). In reviewing the statements on the Nature of Leadership scale, none related to teacher perceptions of a leader establishing an environment that promoted anxiety, excitement or joy. The concepts of encouraging joy, excitement and delight are often overlooked. Studies have shown the negative effect of anxiety on collective efficacy (Goddard, 2002). Teachers working to address the need of all students and ensure all students meet success could be a source of anxiety. Recognizing demographic changes in a school, a leader might see the need to support the teams and faculty as the change may produce anxiety for the teachers.

The study looking for actions a leader might use to increase collective efficacy proved informational. Most importantly, a leader needs to keep in mind that the collective efficaciousness of the faculty does not reflect the collective efficacy of all teams. Variance exists within a school's faculty and the efficacy of teams within the school is not reflected in the overall collective efficacy of the entire faculty. Leaders need to know the collective efficacy of each team. This knowledge would provide a way for leaders to promote higher levels of success for all (Goddard et al., 2004; R. Goddard \& Y. Goddard, 2001; Hipp, 1997; Hoy \& Woolfolk, 1993; Ross \& Gray, 2004).

The study, although correlational, provides ideas for leaders to consider as they determine actions to take to improve schools. When a team or faculty is evincing concerns about their ability to be successful with all students a leader might consider using traits of transformational leadership emphasizing modeling, creating norms to promote culture, working with the school community to determine and steward a common vision, and provide support for all staff; all indicators that have been shown to have a high correlation with collective teacher efficacy.

External threats to efficacy are critical for a leader to note. These may include an increase in the percent of English Language Learners in a school or in a particular department or at a specific grade level. An increase in the percentage of English Language Learners could threaten the efficacy of the staff if the teachers do not feel they have the strategies to ensure success. To combat the negative influence on collective efficacy, a leader could see the importance of being very deliberate about providing support and encouragement to the staff. It would be important to provide feedback and employ the strategies noted by Hill and Lundquist, developing collaborative leadership teams within the school community to support teachers in learning best practice strategies for all leaners, would be important as a means to promote higher levels of collective teacher efficacy. This is also an opportunity for a leader to empower teams or individual teachers, helping the faculty recognize their own potential. Recognizing teacher leaders as leadership teams are formed would be a way of promoting collective teacher efficacy. Sharing successes or having teachers share strategies that work for all provides support for all staff. This feedback has been shown to promote higher levels of efficacy in a school (Hill \& Lundquist, 2008).

\section{References}

Bandura, A. (1977). Self-efficacy: Toward a unifying theory of behavioral change. Psychological Review, 84, 191-215. http://dx.doi.org/10.1037/0033-295X.84.2.191

Bandura, A. (1986). Social foundations of thought and action: A social cognitive theory. Eaglewood Cliffs, NJ: Prentice-Hall.

Bandura, A. (1993). Perceived self-efficacy in cognitive development and functioning. Educational Psychologist, 28(2), 117-148. http://dx.doi.org/10.1207/s15326985ep2802_3

Bandura, A. (1997). Self-efficacy: the exercise of control. New York: W.H. Freeman and Company.

Bandura, A. (2000). Exercise of human agency through collective efficacy. Current Directions in Psychological Science, 9(3), 75-78. http://dx.doi.org/10.1111/1467-8721.00064

Bass, B. (1985). Leadership and performance beyond expectations. The Free Press, New York. 
Bass, B., \& Avolio, B. (1993). Transformational leadership and organizational culture. Public Administrative Quarterly, 17(1), 112-121.

Burns, J. (1978). Leadership. New York: Harper \& Row.

Coburn, C., \& Russell, J. (2008). District policy and teachers' social networks. Education Evaluation and Policy Analysis, 30(3), 203-235. http://dx.doi.org/10.3102/0162373708321829

Coleman, J. (1987). Families and schools. Educational Researcher, 16(6), 32-38. http://dx.doi.org/10.3102/0013189X016006032

Coleman, J. (1988). Social capital in the creation of human capital. American Journal of Sociology, 94 (Supplemental), S95-S120. http://dx.doi.org/10.1086/228943

Dufour, R., \& Eaker, R. (1998). Professional learning communities at work: Best practices for enhancing student achievement. Bloomington, IN: Solution Tree.

Gibson, S., \& Dembo, M. (1984). Teacher efficacy: A construct validation. Journal of Educational Psychology, 76, 569-582. http://dx.doi.org/10.1037/0022-0663.76.4.569

Goddard, R. (2001). Collective efficacy: A neglected construct in the study of schools and student achievement. Journal of Educational Psychology, 93(3), 467-476. http://dx.doi.org/10.1037/0022-0663.93.3.467

Goddard, R. (2002). A theoretical and empirical analysis of the measurement of collective efficacy: The development of the short form. Educational and Psychological Measurement, 61(6), 1071-1084. http://dx.doi.org/10.1177/0013164402062001007

Goddard, R., \& Goddard, Y. (2001). A multilevel analysis of the relationship between teacher and collective efficacy in urban schools. Teaching and Teacher Education, 17, 807-818. http://dx.doi.org/10.1016/S0742-051X(01)00032-4

Goddard, R., Hoy, W., \& Woolfolk, H. A. (2000). Collective teacher efficacy: Its meaning, measure, and effect on student achievement. American Educational Research Journal, 37(2), 479-507. http://dx.doi.org/10.3102/00028312037002479

Goddard, R., LoGerfo, L., \& Hoy, W. (2004). High school accountability: The role of collective efficacy. Educational Policy, 18(3), 403-425. http://dx.doi.org/10.1177/0895904804265066

Hill, J., \& Lundquist, A. (2008). Using leadership teams to elevate English learning. School Administrator, 65, 30-34.

Hipp. K. (1996). Teacher efficacy: Influence of the principal leadership, and student achievement. Paper presented at the Annual Meeting of the American Educational Research Association, New York, NY.

Hipp, K. (1997). Documenting the effects of transformational leadership behavior on teacher efficacy. Paper presented at the Annual Meeting of the American Educational Association, Chicago, IL.

Hoy, W., \& Woolfolk, A. (1993). Teachers' sense of efficacy and the organizational health of schools. Elementary School Journal, 93, 335-372. http://dx.doi.org/10.1086/461729

Leithwood, K. (1992). Transformational leadership: Where does it stand? Educational Digest, 58(3), 17-20.

Leithwood, K. (1993). Contributions of transformational leadership to school restructuring. Paper presented at the Convention of the University Council for Educational Administration., Houston, TX.

Leithwood, K. (2006, October 10). Nature of leadership 95 scale reliabilities, Message posted at prellig@region-12.org.

Leithwood, K. (1996). School restructuring, transformational leadership and the amelioration of teacher burnout. Anxiety, Stress and Coping, 9, 199-215. http://dx.doi.org/10.1080/10615809608249402

Leithwood, K., \& Jantzi, D. (1995). Toward an explanation of how teachers' perceptions of transformational school leadership are formed. Paper presented at the Annual meeting of the American Educational Research Association, San Francisco: CA.

Leithwood, K., \& Jantzi, D. (1999). Transformational school leadership effects: A replication. School Effectiveness and School Improvement, 10(4), 451-479. http://dx.doi.org/10.1076/sesi.10.4.451.3495

Leithwood, K., Jantzi, D., \& Fernandez, A. (April, 1993). Secondary schools teachers' commitment to change: The contributions of transformational leadership. Paper presented at the American Educational Research Association, Atlanta, GA. 
Leithwood, K, Jantzi, D., \& Steinbach, R. (1999). Changing leadership for changing times. Buckingham: Open University Press.

Leithwood, K., \& Riehl, C. (2003). What we know about successful school leadership. Retrieved, April 13, 2006, from Task Force on Research in Education: www.cepa.gse.rutgers.edu/whatweknow.pdf

Leithwood, K., \& Sun, J. (2013). The nature and effects of transformational school leadership: A meta-analytic review of unpublished research. Educational Administration Quarterly, 48(3), 387-423. http://dx.doi.org/10.1177/0013161X11436268

Lewandowski, K. (2005). A study of the relationship of teachers' self-efficacy and the impact of leadership and professional development. Unpublished doctoral dissertation, Indiana University of Pennsylvania.

Marks, H., \& Printy, S. (2003). Principal leadership and school performance: An integration of transformational and instructional leadership. Educational Administration Quarterly, 39, 370-397. http://dx.doi.org/10.1177/0013161X03253412

Milner, H. (2002). A case study of an experienced teacher's planning and efficacy for student achievement. Unpublished Dissertation. The Ohio State University, Columbus, OH.

Moolenaar, N., Sleegers, J., \& Daly, A. (2012). Teaming up: Linking collaboration networks, collective efficacy, and student achievement. Teaching and Teacher Education, 28, 251-262. http://dx.doi.org/10.1016/j.tate.2011.10.001

National Association of Educational Progress. (2005). State Profiles. Retrieved July 14, 2007, from National Center for Educational Statistics Web site: http://nces.ed.gov/nationsreportcard/states/profile.asp

Printy, S., Marks, H., \& Bowens, A. (2009). Integrated leadership: How principals and teachers share transformational and instructional influence. Journal of School Leadership, 19(5), 504-532.

Ross, J. (1992). Teacher efficacy and the effects of coaching on student achievement. Canadian Journal of Education, 17(1), 51-65. http://dx.doi.org/10.2307/1495395

Ross J., \& Gray, P. (2004). Transformational leadership and teacher commitment to organizational values: The mediating effects of collective teacher efficacy. Paper presented at the Annual Meeting of the Educational Research Association, San Diego, CA.

Tschannen-Moran, M., Woolfolk Hoy, A., \& Hoy, W. (1998). Teacher efficacy, its meaning and measure. Review of Educational Research, 68, 202-248. http://dx.doi.org/10.3102/00346543068002202

Tschannen-Moran, M., \& Woolfolk Hoy, A. (2001). Teacher efficacy: Capturing and elusive concept. Teaching and Teacher Education, 17, 783-805. http://dx.doi.org/10.1016/S0742-051X(01)00036-1

Waters, J., Marzano, R., \& McNulty, B. (2004). Leadership That Sparks Learning. Educational Leadership, 61(7), 48-51.

\section{Copyrights}

Copyright for this article is retained by the author(s), with first publication rights granted to the journal.

This is an open-access article distributed under the terms and conditions of the Creative Commons Attribution license (http://creativecommons.org/licenses/by/3.0/). 